Sharif University of Technology
Scientia Iranica
Transactions A: Civil Engineering
SCIENTIA
IRAN I CA

\title{
Multi-laminate rate-dependent modelling of static and dynamic concrete behaviors through damage formulation
}

\author{
S.A. Sadrnejad and M.R. Hoseinzadeh* \\ Civil Engineering Faculty, K. N. Toosi University of Technology, No. 1346, ValiAsr Ave., Mirdamad Cross, Tehran, Iran.
}

Received 31 January 2017; accepted 30 October 2017

\author{
KEYWORDS \\ Multi-laminate; \\ Rate-dependent; \\ Damage; \\ Nonlinear behavior; \\ Quasi-brittle \\ materials; \\ Concrete.
}

\begin{abstract}
Mathematical simulation of the nonlinear tri-dimensional mechanical behavior of quasi-brittle materials like concrete is one of the biggest challenges in the engineering science. It is vital to have the knowledge of the response of concrete specimens subjected to low and high strain rate deformations in the analysis of concrete structures under the static and dynamic loading cases. The behavior of this material is generally known to be strain-rate-sensitive. Among different phenomena with different orientations, the multiplane models, like multi-laminate, using a constitutive equation in a vectorial form rather than tensorial form by means of capturing interactions can meet this goal adequately. This paper suggests a robust rate-dependent damage based model in the multi-plane framework accomplished with minimum parameters for calibration, which is appropriate for engineering purposes. Damage formulation was done on the basis of two types of essential damage, namely axial damage and shear damage, that could basically happen on each sampling plane and based on this concept, two new axial and shear damage functions were proposed. Model verification was performed under different compressive and tensile loading rates, comparing the results of the proposed model with the experimental data and Mohr-Coulomb failure criterion envelope line.
\end{abstract}

(C) 2019 Sharif University of Technology. All rights reserved.

\section{Introduction}

Concrete belongs to a group of the so-called quasibrittle materials, which are neither plastic nor brittle, and heterogeneous structure specifies its complicated behavior on the macro level with a highly nonlinear behavior. Nowadays, within the scope of composite materials, concrete is considered as a well-known material, whose manufacturing, behavior, and application

\footnotetext{
*. Corresponding author. Tel.: +982188881128 Fax: +982188779476

E-mail address: mhosseinzadeh@mail.kntu.ac.ir (M.R. Hoseinzadeh).
}

doi: $10.24200 /$ sci.2017.4581 have been thoroughly described. Although the vast research over several decades strongly supports this claim, thus far, no unique answer, i.e., exact solution, to how to model the complex processes in fracture of concrete has been achieved. In order to model concrete fracture, three groups of study are employed in finite element codes with varying levels of effectiveness: theory of plasticity, fracture mechanics, and continuum damage mechanics. They usually have not been able to completely simulate all the aspects of the complicated nature of concrete fracture. In fact, each theory explains only some behavior aspects.

Concrete fracture modeling can be classified in three categories: macroscopic invariant-based models, mesoscopic semi-multi-scale models such as microplane or multi-plane, and discontinuous models. 
Macroscopic invariant-based models lose some of the important features of material behavior such as orientation dependency. The particle properties and interaction laws are studied into discontinuous models, which are also often known as molecular dynamics for granular materials; this results in the combined behavior of the enormous-particle system [1]. The application of these models to the daily engineering practices still seems to be ambitious for the massive structures. It is worthwhile to mention that the utilization of discrete fine-scale models, which are the sub-category of discontinuous models in the form of Lattice Discrete Particle Model (LDPM), is limited due to the imposition of a relatively large computational burden, which is followed by huge computational cost. The formulation of LDPM is done through the discrete models, which are unknown discontinuous displacement fields, except at a finite number for the centers of aggregate particles [2], and simulates behavior of the materials at the level of coarse aggregate pieces [3]. Computational homogenization has recently been proposed as an effective solution for quasi-brittle materials [4], specially concrete [5], in order to overcome these difficulties. Nowadays, the mesoscale modeling is the best modeling method because of the high computational power of computers and the significance of high accuracy in research [6]. Hence, in the present research, the researchers address the mesoscopic models such as multi-plane models.

One of the most important aspects of concrete behavior is strain softening, which is observed under both static and dynamic loadings. In strain softening, after the peak strength, the stress decreases whereas the strain increases due to the propagation and coalescence of micro-cracks, micro-voids, and similar defects. The structure can collapse when this micro-damage increases under loading and becomes cracks [7].

Above all, the behavior of quasi-brittle materials such as concrete is generally known to be strainrate-sensitive and numerous types of structures may be exposed to dynamic loading at a wide range of strain rates, which are why the dynamic behavior of plain concrete has been extensively studied. Thus, it draws particular interest to identify both the static and dynamic behaviors of concrete and, due to the generally known rate dependency of the concrete behavior, modeling of concrete becomes much more complex for dynamic loading. Although for many decades, researchers have been trying to carry out extensive research on the modeling of the concrete behavior under static or quasi-static loadings, many aspects of its behavior still belong to the research area and recent research has begun to examine the aspects of its behavior under high rate loading, so that it has become a topic of great interest in recent years [8].

A great number of studies on strain-rate sensitiv- ity of concrete have been carried out since Abrams [9] reported the strain rate sensitivity of concrete during the compression test in 1917 for the first time. As it has been shown in several experimental [10-13], theoretical [14,15], and numerical [16-19] studies, the loading rate significantly influences the resistance and failure modes of concrete structures in a way that the strength of concrete may become more than that of quasi-static loading in case of high strain rates caused by highvelocity loading such as impacts.

It is generally accepted that the Dynamic Increase Factor (DIF) is defined by the ratio of the dynamic strength to the static strength of the material. Based on experimental results, some empirical compressive DIF formulae have been developed. For example, the DIF relations recommended by CEB-FIB-1993 [20] for concrete material under dynamic compression are:

$$
\begin{aligned}
& C D I F=f_{c d} / f_{c s}=\left(\dot{\varepsilon}_{d} / \dot{\varepsilon}_{c s}\right)^{1.026 \alpha} \quad \text { for } \quad \dot{\varepsilon}_{d} \leq 30 / s, \\
& C D I F=f_{c d} / f_{c s}=\gamma\left(\dot{\varepsilon}_{d} / \dot{\varepsilon}_{c s}\right)^{1 / 3} \quad \text { for } \quad \dot{\varepsilon}_{d}>30 / s,
\end{aligned}
$$

where $f_{c d}$ is the dynamic compressive strength at the strain rate $\dot{\varepsilon}_{d}$ :

$$
\begin{aligned}
& \dot{\varepsilon}_{c s}=30 \times 10^{-6} / s, \\
& \log \gamma=6.156 \alpha-2, \\
& \alpha=\left(5+9 f_{c s} / f_{c 0}\right)^{-1},
\end{aligned}
$$

in which $f_{c s}$ is the static compressive strength, and $f_{c 0}=10 \mathrm{MPa}$.

The new dynamic increase factor for the tensile strength is given by Hao and Hao [21]:

$$
\begin{aligned}
& \text { TDIF }=f_{t d} / f_{t s}=0.26 \log \dot{\varepsilon}_{d}+2.06 \\
& \text { for } \dot{\varepsilon}_{d} \leq 1 / s \\
& T D I F=f_{t d} / f_{t s}=2 \log \dot{\varepsilon}_{d}+2.06 \\
& \text { for } 1 / s<\dot{\varepsilon}_{d} \leq 2 / s, \\
& T D I F=f_{t d} / f_{t s}=1.44331 \log \dot{\varepsilon}_{d}+2.2276 \\
& \text { for } 2 / s<\dot{\varepsilon}_{d} \leq 150 / \mathrm{ss} .
\end{aligned}
$$

Based on Eqs. (1) and (2), Figure 1 indicates that in comparison with compression, the tensile behavior of concrete under different strain rates is more uniform and is higher under a given same strain rate for the DIF factor.

In this paper, in Section 2, a realistic and robust rate-dependent continuum damage based model in the 


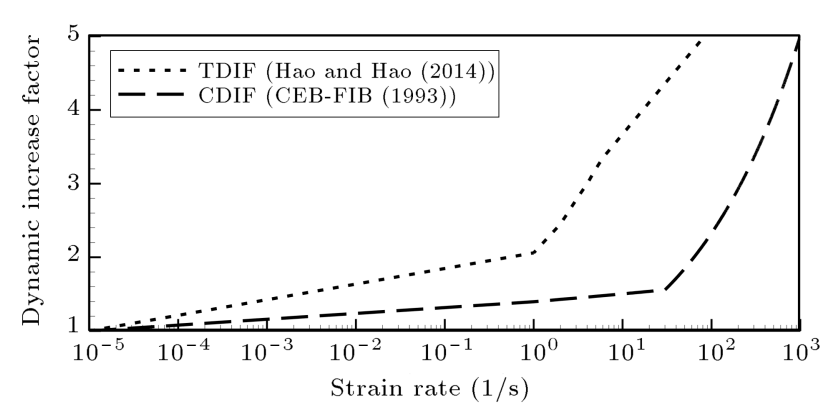

Figure 1. Position of integration points on the unit surface of sphere.

multi-laminate framework is proposed. In Section 3, in order to establish the validity of the proposed concrete material model, verification studies of analytical results with experimental evidence from the stress-strain response of concrete specimens under different loading conditions are carried out. Finally, some noticeable conclusions are presented in Section 4.

\section{Constitutive equations for the rate-dependent multi-laminate elastic-damage model}

With respect to what was mentioned in the previous section, the researchers pay attention to the mesoscopic models (multi-plane models) as semi-multi-scale with a discrete set of directions [22] based on the concept of angular discretization of space [23]. They are nowadays considered as a powerful tool for numerical simulation of the geo and geo-like materials such as concrete [24]. It should be noted that the fundamental idea of Eq. (3) has its origin in the slip theory of plasticity by Taylor (1938), who was the first to employ this theory for modeling the behavior of polycrystalline metals. It is a simplified relation between microscale and macroscale mechanicals behavior of a material and can be integrated from the behavior of material on several so-called "integration planes," "micro-planes," "contact planes," or "sampling planes," in which the damage function or yield surface and plastic potential are defined individually with various orientations. In recent decades, there have been a great number of developments in constitutive models, which are on the basis of the concept of discrete set of orientations. Microplane model was first proposed by Bazant \& Oh [25] in quasi-brittle materials simulation and multi-laminate theory was first suggested by Pande \& Sharma [26] for clay behavior description; they are considered as two of the most important conceptually similar families in this kind of models. In a straightforward manner, without mathematical complexity, both frameworks are able to consider inherent and induced anisotropies as a significant feature. Multi-plane models with different formulations have also been successfully developed for other materials such as polycrystalline metals, rock, soil, rigid foam, shape memory alloys, fiber-reinforced concrete, composite laminates, etc. [27]. Some great advantages of multi-plane models were reviewed in Bazant et al. [28] and Brocca \& Bazant [29]. The history of the trend of development in multi-plane models for modeling concrete behavior has been briefly explained in the study by Caner \& Bazant [30]. In the study by Sadrnejad [31], the basic formulations of multi-laminate framework have been well explained. It is very important to mention that the vertex effects (in which the inelastic deformation increments are parallel to the current loading surface in the stress space) are fundamentally overcome in the multi-plane models, which represent multi-surface loading with some vectorial limit surfaces at each sampling plane [30]. Because of the principles of tensorial macro-models, which have one or a few loading surfaces, this effect is essentially overlooked [30]. This effect has been experimentally shown in Caner et al. [32], which is very important under dynamic loads. Furthermore, unlike tensorial form, in order to simulate the nonlinear material behavior of concrete, which significantly occurs in both the service and the failure ranges [22], the strain dependence of the yield limit can be easily taken into account in the vectorial component from one generic sampling plane [22,30]. Unlike the multilaminate models in which the projection of macroscopic stresses on the sampling planes (static constraints) is usually used, the micro-plane models use the projection of macroscopic strains (kinematic constraints) [33]. The proposed model is double-constraint multi-plane, which benefits from both the static and kinematic constraints and satisfies both equilibrium and compatibility conditions, simultaneously. The common differences between micro-plane and multi-laminate models are summarized as follows [23]. First, in multilaminate models, the calculation of behavior aspects at microscopic level is done without the decomposition of macroscopic tensors, while to this end, micro-plane models use the deviatroic-volumetric decomposition. Second, in micro-plane models, successive events of damage occur until all the microplanes are under damage function, while in the multi-laminate models, damage concentrates on one or a few planes and the rest of the planes remain elastic. Third, in the microplane models, in regard to the macroscopic principal stresses, the shape of the damage function needs to be controlled as a function of the orientation. Considering the above-mentioned differences, making the microplane models is mathematically more complex and that is why the multi-laminate models have been developed in this study.

In this paper, in each integration point, the macro-strain tensor without splitting volumetric and deviatoric parts is projected on the sampling planes 
of all possible orientations, which are an arbitrary tangent plane on the surface of a unit sphere; then, by introducing on-plane constitutive laws, the stress vector components are calculated and finally, the stress tensor is identified by transferring every stress vector upon any of the sampling planes to the global coordinate system. Then, they should be integrated on the surface of the unit sphere. In numerical computations, this integral is approximated according to some of the optimal Gaussian integration formulae for a spherical surface, which replace the integral by a weighted sum over a finite number of sampling planes [30]. This approximation may be written as follows:

$$
\int_{\Omega} f(x, y, z) d \Omega \approx 4 \pi \sum_{k=1}^{q} w_{k} f_{k}\left(x_{k}, y_{k}, z_{k}\right),
$$

where $\Omega$ is surface of a unit hemisphere centered at the material point equation; $q$ is the number of sampling planes; $w_{k}$ is the weights factor normalized such that $\sum_{k=1}^{q} w_{k}=0.5[25,34]$. Here, in order to enhance the accuracy of numerical integration, $2 \times 17$ sampling planes are applied. Direction cosines and weights of the integration points have been defined in Sadrnejad and Hoseinzadeh's paper [35]; also, in Figure 2, their positions are shown.

The sampling plane orientation is characterized by the unit normal vector $\vec{n}$ with components $n_{i}$, with the subscript $i$ referring to the global Cartesian coordinates $x_{i}(i=1,2$, and 3$)$. In the formulation with a kinematic constraint, which makes it possible to describe softening behavior of plain concrete in a stable manner, the strain vector $\overrightarrow{\{\varepsilon\}}$ or $\{\varepsilon\}$ on the sampling planes is the projection of the strain tensor $\varepsilon_{i j}$ (Figure $3)$.

Based on Eq. (4), the stress vector $\{\sigma\}$, which contains the components $\sigma_{N}, \sigma_{M}$, and $\sigma_{L}$, is calculated

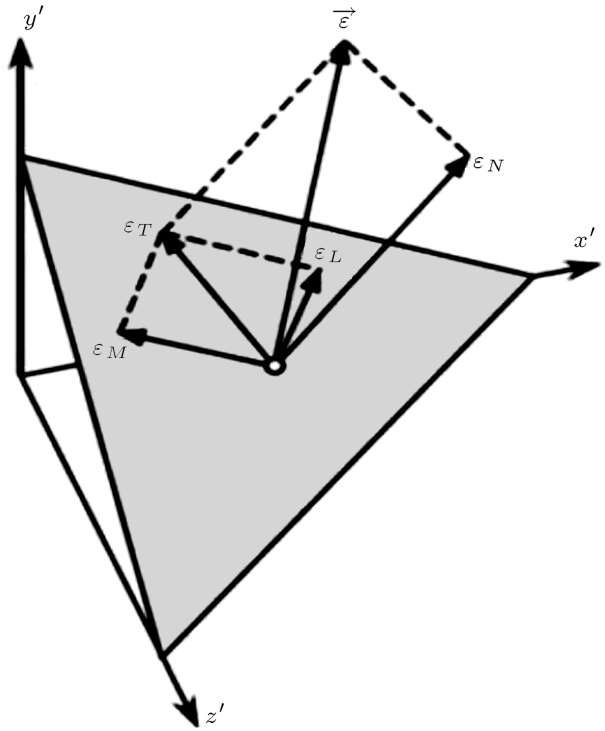

Figure 3. Strain components on a sampling plane [30].

by defining on-plane constitutive laws between strain and stress vectors once the strain vector $\{\varepsilon\}$, which contains the components $\varepsilon_{N}, \varepsilon_{M}$, and $\varepsilon_{L}$ on each sampling plane, is obtained. Eq. (4) is used for the simulation of both linear and non-linear behaviors in a way that the theory of elasticity is used for modeling linear elastic behavior, while based on continuum damage mechanics, in order to stimulate non-linear aspects, elastic properties of the material are reduced in each plane by damage matrix, which is specific to the same sampling plane.

$$
\{\sigma\}=[D]\{\varepsilon\},
$$

in which $[D]$ is the modulus matrix of each sampling plane and defined according to Eq. (5) shown in Box I. The normal and shear stiffness constants $E_{N}$ and $E_{T}$ on the sampling planes are as follows when the normal

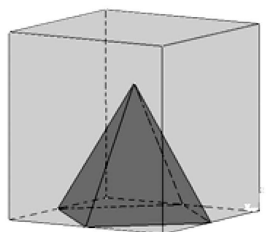

Planes $1,2,3,4$

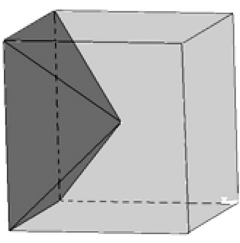

Planes 5, 6

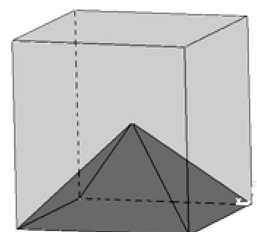

Planes $7,8,9,10$

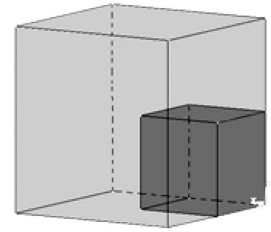

Planes $11,12,13$

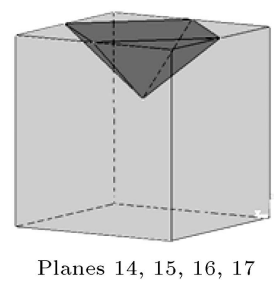

(a)

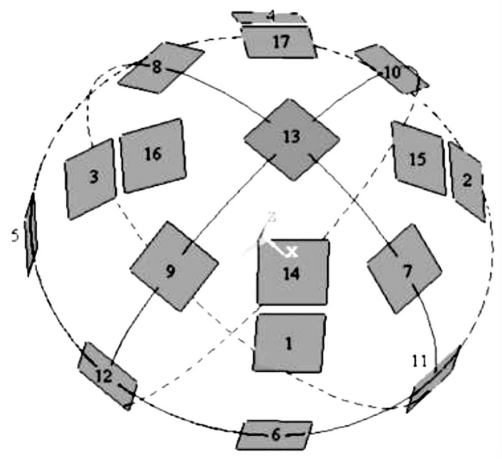

(b)

Figure 2. Position of $2 \times 17$ integration points (sampling planes): (a) at a cube and (b) on the surface of unit sphere. 


$$
[D]=\left[\begin{array}{ccc}
1-w_{\text {axial }}\left(x\left(\varepsilon_{a x}\right)\right) & 0 & 0 \\
0 & 1-w_{\text {shear }}\left(x\left(\varepsilon_{s h}\right)\right) & 0 \\
0 & 0 & 1-w_{\text {shear }}\left(x\left(\varepsilon_{s h}\right)\right)
\end{array}\right]\left[\begin{array}{ccc}
E_{N} & 0 & 0 \\
0 & E_{T} & 0 \\
0 & 0 & E_{E}
\end{array}\right] .
$$

Box I

strains $\varepsilon_{N}$ are not split into their volumetric and deviatoric parts [36]:

$$
\begin{aligned}
& E_{N}=E /(1-2 \vartheta), \\
& E_{T}=E_{N} \cdot(1-4 \vartheta) /(1+\vartheta),
\end{aligned}
$$

where $E$ is Young's modulus on the macro-level; $\vartheta$ represents Poisson's ratio; and $E_{N}=K / 3$, in which $K$ is the bulk modulus.

In Eq. $(5), w_{\text {axial }}\left(x\left(\varepsilon_{a x}\right)\right)$ and $w_{\text {shear }}\left(x\left(\varepsilon_{s h}\right)\right)$ are the new damage functions. In fact, the damage formulation has been built based on two types of fundamental damage, namely axial damage and shear damage, which can occur on each sampling plane. In this new formulation, according to the damage theory, the values of both the new damage functions, namely axial damage function modulus. $w_{\text {axial }}$ and shear damage function, $w_{\text {shear }}$, which are dependent on axial and shear strains, vary in each plane between zero to one; zero represents the undamaged state, i.e., no crack initiation on the sampling plane, and one refers to the fully damaged state, i.e. the occurrence of complete crack opening (in mode I) or sliding (in mode II) on the sampling plane. These new damage functions may be written as follows:

$$
\begin{gathered}
1-w_{\text {axial }}=\left(1-w_{a x}^{\prime}\right) \times\left[1-w_{s h}^{\prime} \times H\left(x\left(\varepsilon_{a x}\right)\right)\right], \\
w_{a x}^{\prime}=H\left(x\left(\varepsilon_{a x}\right)\right) \times\left[1-\exp \left(-a_{a x} \times x\left(\varepsilon_{a x}\right)\right],\right. \\
1-w_{\text {shear }}=\left(1-w_{s h}^{\prime}\right) \\
\times\left[1-w_{a x}^{\prime} \times \operatorname{sgn}\left(-\varepsilon_{a x} \times H\left(\varepsilon_{s h}\right)\right)\right], \\
w_{s h}^{\prime}=H\left(x\left(\varepsilon_{s h}\right)\right) \times\left[1-\exp \left(-a_{s h} \times x\left(\varepsilon_{s h}\right)\right] .\right.
\end{gathered}
$$

In Eqs. (7) and (8), $w_{a x}^{\prime}$ is the axial damage function, which only results from axial strain, and $w_{s h}^{\prime}$ is the shear damage function that is only due to shear strain.

In the above equations, $H(t)$ and $\operatorname{sgn}(t)$ are the Heaviside step and sign functions, respectively, for an arbitrary variable such as ' $t$ ', and $x(\varepsilon)$ is:

$$
x(\varepsilon)=\left(|\varepsilon|-\left|\varepsilon_{0}\right|\right) /\left|\varepsilon_{0}\right|,
$$

in which $\varepsilon$ and $\varepsilon_{0}$ are strain component and damage threshold strain, respectively.
The model parameters $a_{a x}$ and $a_{s h}$ in Eqs. (7) and (8) are calibrated according to laboratory results and obtained for each specific concrete. $\varepsilon_{a x}$ is axial strain and $\varepsilon_{s h}$ is magnitude of shear strain. These strain components may be written as follows:

$$
\varepsilon_{a x}=\varepsilon_{N} \quad \varepsilon_{s h}=\varepsilon_{T}=\sqrt{\varepsilon_{M}^{2}+\varepsilon_{L}^{2}} .
$$

Based on Eqs. (7) and (8), the damage functions for each plane are dependent on two key factors; the first one is the parameters $a_{a x}$ and $a_{s h}$, which are constant values for all sampling planes in each test, and the other one is function $x(\varepsilon)$, which has separate values for each plane considering the fact that the magnitude of its strain components is different from other planes. Consequently, the damage functions of each sampling plane are specific to the same plane and different from those of other planes. This formulation is crucial to describing concrete behavior, because cracks tend to fracture in configurations under combined normal and shear damages; thus, it is important to explore crack propagation under both mode I (opening) and mode II (sliding) [37].

Now, the stress tensor $[\sigma]$ from the stress vectors on the sampling planes can be obtained. To do so, it is first necessary to transfer every stress vector on the plane from local coordinate to the global coordinate system and then, add them up according to their weightings.

$$
[\sigma]=6 \sum_{k=1}^{17} w_{k}[L]_{k}^{T}\{\sigma\}_{k}
$$

In the above equation, $[L]$ is the transition matrix of each sampling plane.

For each plane, the compliance matrix, $[C]$, may be defined as follows:

$$
[C]=[D]^{-1} \text {. }
$$

Finally, for each integration point, the macro compliance matrix $[\bar{C}]$ and the macro modulus matrix $[\bar{D}]$ are defined according to Eqs. (13) and (14), respectively:

$$
\begin{aligned}
& {[\bar{C}]=6 \sum_{k=1}^{17} w_{k}[L]_{k}^{T}[C]_{k}[L]_{k},} \\
& {[\bar{D}]=[\bar{C}]^{-1}}
\end{aligned}
$$


When a specimen is quickly loaded, no rate sensitivity can be observed in linear elastic range of material, whereas there is a considerable effect of loading rate on structural response in case of the material, e.g., concrete, exhibiting damage and fracture phenomena [38]. As a result, it is concluded that rate sensitivity might be closely connected with damage and softening of the material, i.e. the more the damage, the stronger will be the effect of loading rate on structural response [38]. Although thus far, there has been no consensus on the mechanism of strain rate sensitivity of concrete, due to 4 major reasons, the structural concrete resistance increases once the strain rate increases: (a) the lateral inertia forces of micro-cracking, which cause increase in the critical strain, (b) the propagation of microcracks through aggregate particles rather than distribution of macro-cracks around them, (c) formation of more cracks and fragments, and (d) the viscosity of free water in pores of concrete [18,39-42]; and these result in retardation in crack propagation or retarded damage. The concepts of retarded damage first used in stress-strain relation were given by Eibl \& SchmidtHurtienne [43] and Haussler-Combe \& Kitzig [44].

Accordingly, concrete, as a damageable material, is a highly rate-dependent material [45]. Making use of the strain rate effect in the design of structures demands the knowledge of both stress-strain relations and the corresponding strength properties in an energetic setting with a considerable variation of strain rates in time. Also, the common use of dynamic strength increase factors depending on an assumed constant strain rate value seems inappropriate. Phenomenological rules should be replaced with sound approaches on the basis of physical behavior [46].

Constitutive laws for high strain rates are generally developed as extensions of laws for the quasi-static case. It is generally accepted that when the strain rate increases, the ultimate stress (strength), the elastic (secant) modulus, and the peak strain increase [47]. For this purpose, based on CEB-FIP-2010 [48] and some calibrations according to laboratory dynamic tests, $E$ and $\varepsilon_{0}$ are introduced as the functions of the equivalent strain rate $\dot{\varepsilon}_{e q}$ on each sampling plane as follows:

$$
E\left(\dot{\varepsilon}_{e q}\right)=\left(\dot{\varepsilon}_{e q} / \dot{\varepsilon}_{\text {static }}\right)^{0.026} \times E_{\text {static }}
$$

$\dot{\varepsilon}_{\text {static }}$ is the strain rate corresponding to the static loading, equal to 0.00003 and 0.000003 in compression and tension, respectively; $E_{\text {static }}$ is the elastic modulus corresponding to the static loading, equal to $E$.

$$
\varepsilon_{0}\left(\dot{\varepsilon}_{e q}\right)=b \times\left(\dot{\varepsilon}_{e q} / \dot{\varepsilon}_{\text {static }}\right)^{0.02} \times \varepsilon_{0 \text { static }}
$$

$\varepsilon_{0 \text { static }}$ is the static damage threshold strain on the macro-level, equal to $\varepsilon_{0}$. Parameter ' $b$ ' should be calibrated according to laboratory dynamic tests to

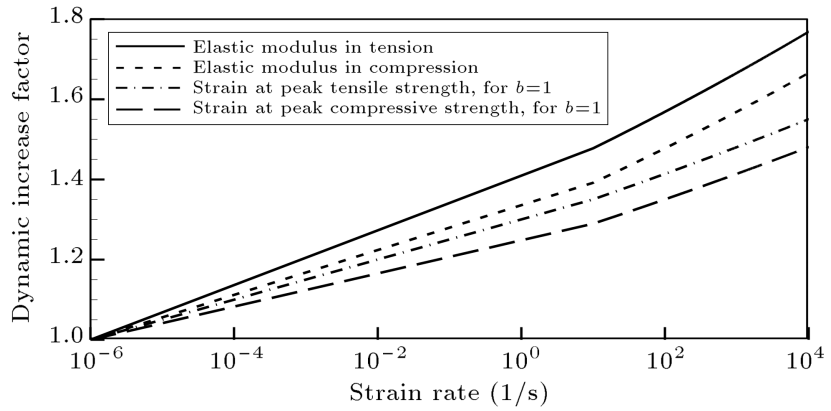

Figure 4. Strain rate effects on the different aspects of the behavior of concrete.

give proper results. For each plane, the equivalent strain is defined as the magnitude of strain vector:

$$
\varepsilon_{e q}=\sqrt{\varepsilon_{N}^{2}+\varepsilon_{M}^{2}+\varepsilon_{L}^{2}} .
$$

Figure 4 illustrates the effect of strain rate on different aspects of the behavior of concrete.

Based on what was mentioned above, as another type of multi-plane models and an improved form of the presented model in [24], the researchers have employed a double-constraint formulation. In order to simplify the calibration, while the obtained results are consistent with the experimental observations, through proposing more elaborate damage functions, the number of parameters of the model of Labibzadeh and Sadrnejad [24] is reduced from 11 to 3 . In addition, in order to enhance the accuracy of the simulation without volumetric-deviatoric split of strain tensor and its subsequent problems, $2 \times 17$ micro-planes are used in each integration point and the modulus matrix of each plane is multiplied by diagonal damage matrix, which includes two parameters of axial damage and shear damage, while in the model of Labibzadeh and Sadrnejad [24], $2 \times 13$ micro-planes are used in each integration point, and modulus matrix of each plane is multiplied by only scalar damage parameter. Hence, the new proposed model is even able to identify the type of damage dominant in the planes. Above all, the strain rate-dependent behavior has been simulated in this paper.

It should be noted that in the current version of the model, local stress-strain relations without definition of characteristic lengths are adopted to simulate the inelastic behavior of concrete under tension and compression. This strategy may lead to mesh-sizedependent solutions, since the zone of localized strains depends on size of the finite elements [49-52]. However, the numerical simulations addressed in this study are restricted to the uniaxial and triaxial states of stresses. In this type of simulations, the zones of localized strains are assumed to be diffused, so the analysis does not depend on the element size [53-55]. In the future developments, the model needs to be regularized by 
introducing the characteristic lengths in tension and compression into the constitutive equation.

\section{Verification studies}

Verification studies of analytical results with experimental evidence from the stress-strain response of concrete specimens under static and dynamic loadings with different conditions are presented below so as to assess the validity of the proposed concrete material model. In this paper, axial compression and tension strain/stress have been assumed positive and negative, respectively, and there are 3 free and easily adjustable material parameters which make it possible for the proposed model to simulate compressive- or tensilerate-sensitive strength, the corresponding strain, the hardening or softening branch, and the hydrostatic compression curve. In all tests discussed in the paper, the model parameters of $a_{a x}$ and $a_{s h}$ are taken equal to 0.5 and 0.1 , respectively.

\subsection{Static loading}

In compression, concrete indicates a certain nonlinear behavior with an inelastic irreversible deformation. In the pre-peak stage of concrete response in uniaxial compression, a nonlinear stage is seen and followed by a softening stage, both of which are dependent on the strength class [56]. As can be seen in Figure 5, there is a good agreement between the results achieved by the proposed multi-laminate model and tests data from Van Mier [57] and Karsan \& Jirsa [58] under uniaxial compression test. Figure 6 shows a reasonably good fit of test data of Van Mier [59] for the volume expansion of concrete under uniaxial compression. A close fit for both the peak region of the data and the post-peak expansion has been captured.

As compared to uniaxial compression, concrete is a pressure-sensitive material, which shows increase in strength and ductility under multi-axial compression. In the Conventional Tri-axial Compression test (CTC test), the hydrostatic pressure is primarily used on the specimen to a certain level and then, the axial compression is increased while the lateral or confining pressure is held constant. Thus, in these tests, there is

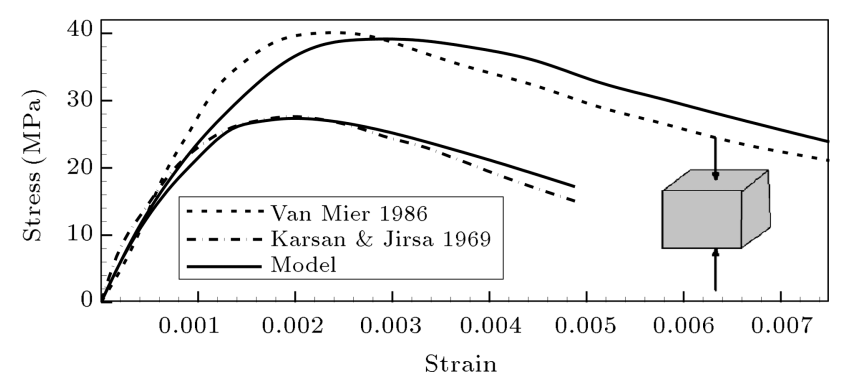

Figure 5. Uniaxial compressive loadings compared with experimental results.

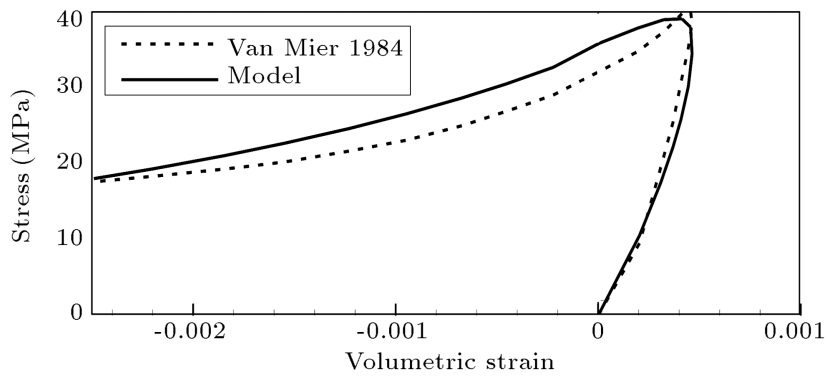

Figure 6. Model response for the volume expansion under uniaxial compressive loading compared with experimental result.

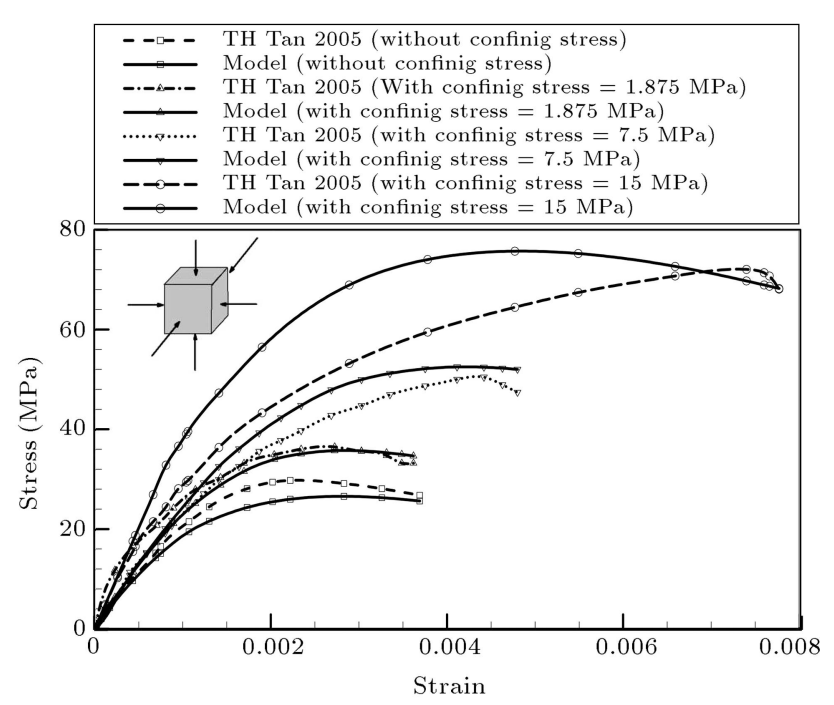

Figure 7. Model response for tri-axial compressive loadings compared with experimental results.

not any shear strain on the sampling planes up to the certain level of hydrostatic compression. The ability of the model to capture this behavior is verified by comparison with experimental data by TH Tan [60] (see Figure 7).

Experimental tests clearly show that concrete in tension is easily broken and after the initiation of the crack, the concrete develops a softening behavior with rotting of tensile strength with the widening of the cracking process. Because of the descent in crack shear stress transfer and aggregate interlock, the crack opening procedure occurs [56]. Figure 8 presents uniaxial tension test data from Petersson [61] for two different concretes and their fits by the present model.

Now, in order to present another evidence for the accuracy of the proposed model in the specimen behavior prediction, failure states of sampling planes in different orientations are compared by Mohr-Coulomb failure criterion envelope line. The Mohr-Coulomb failure criterion represents a set of linear envelopes, generally applied to materials for which the compressive strength is much more than the tensile strength. 


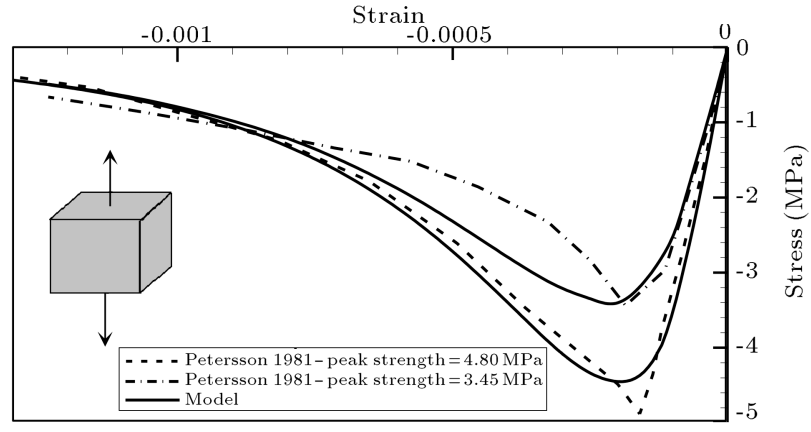

Figure 8. Model response for uniaxial tensile loadings compared with experimental results.

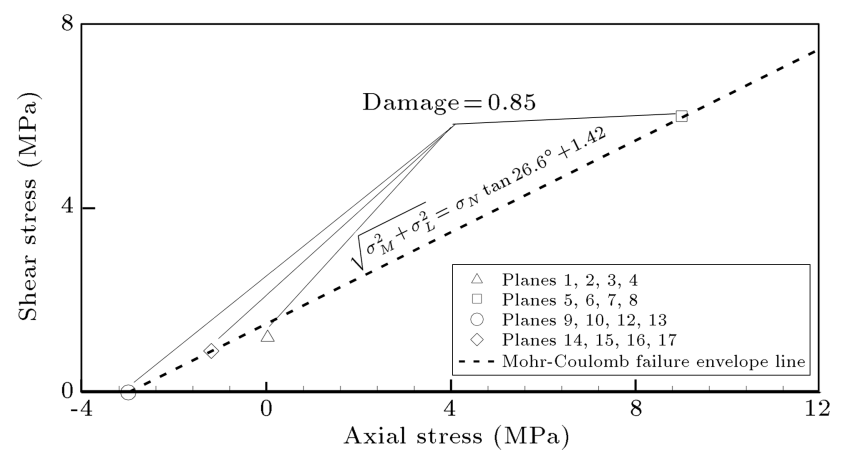

Figure 9. Failure state of each sampling plane compared with Mohr-Coulomb failure envelope line in the Van Mier's compression test.

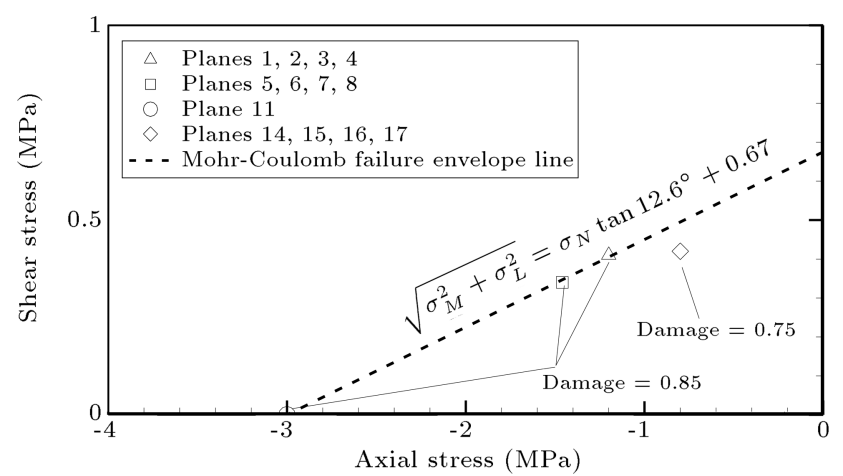

Figure 10. Failure state of each sampling plane compared with Mohr-Coulomb failure envelope line in the Petterson's tension (with peak strength of $3.45 \mathrm{MPa}$ ) test.

This set is obtained from a plot of the shear strength of a material versus the applied normal stress at failure state. For this purpose, it has been assumed that if magnitude of each of axial or shear damages on the sampling plane reaches 0.85 , it experiences failure. For the Van Mier's compression and Petterson's tension (with peak strength $=3.45 \mathrm{MPa}$ ) tests, the states of axial and shear stresses of sampling plane are compared by Mohr-Coulomb failure envelope line in Figures 9 and 10, respectively. As it is obvious in Mier's compression test (Figure 9), sampling plane 11 and in Petterson's experiment (Figure 10), sampling planes $9,10,12$, and 13 do not experience failure due to pure compressive axial stress. In addition, it is clear that in Figure 10, at the end of the Petterson's tension experiment, the magnitude of damage has been 0.75 on sampling planes $14,15,16$, and 17 ; hence, the state of these sampling planes is below Mohr-Coulomb failure envelope line.

\subsection{Dynamic loading}

Under the influence of compression, the DIF could be about 1.5 and 3 in the range of $\varepsilon<10^{-1} 1 / \mathrm{s}$ and $\varepsilon \geq 10^{-1} 1 / \mathrm{s}$ respectively; and under the influence of tension, the DIF could achieve the values of 2 in the range of $\varepsilon \leq 10^{0} 1 / \mathrm{s}$ and 9 in the range of $\varepsilon \geq 10^{2} 1 / \mathrm{s}$ as well [42]. Thus, evolution of damage is retarded in case of high strain rates if damage is used to describe micro-cracking. In order to show the ability of the proposed model for dynamic behavior simulation, the stress-strain responses of concrete specimens under different loading rates are presented below.

A series of Split Hopkinson Pressure Bar (SHPB) experiments are carried out in order to obtain the dynamic stress-strain behavior of mortar in the experimental study by Grote et al. [62]. This series of experiments are reliable with regard to elastic modulus variations, based on strain rate variations [63]. The strain rates obtained range from 250 to $15001 / \mathrm{s}$. There is a good agreement between the results of the proposed model and dynamic tests data from Grote et al. [62] at four different strain rates, as can be seen in the Figure 11. It is obvious that the compressive strength increases with increase in strain rate. At a strain rate of $\dot{\varepsilon}=15001 / \mathrm{s}$, the compressive strength is $160 \mathrm{MPa}$ or approximately 3.5 times the quasi-static strength of $46 \mathrm{MPa}$. The strain-softening after the peak stress, reflecting fragmentation and granular flow, is indicated in the curves [62].

Figure 12 shows the response of the rate- dependent damage model in uniaxial tension tests carried out

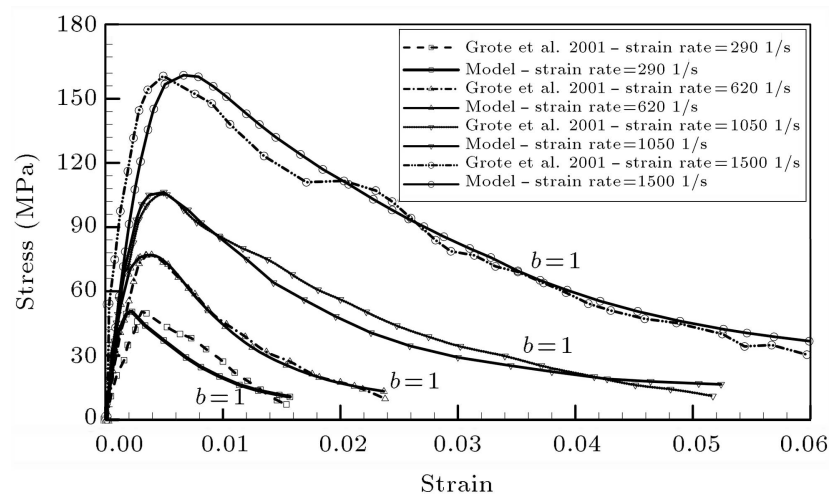

Figure 11. Model response for several compressive strain rates compared with experimental results of Grote et al. (2001). 


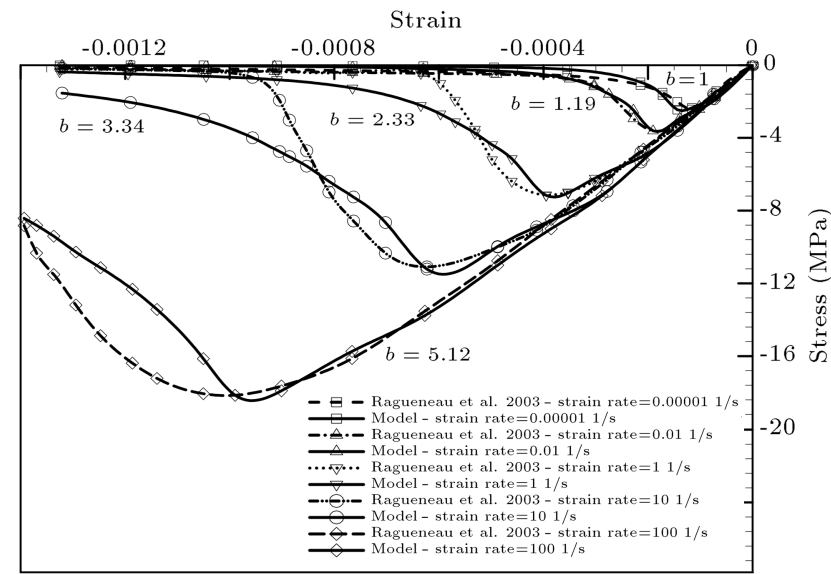

Figure 12. Model response for several tensile strain rates compared with model results of Ragueneau et al. (2003).

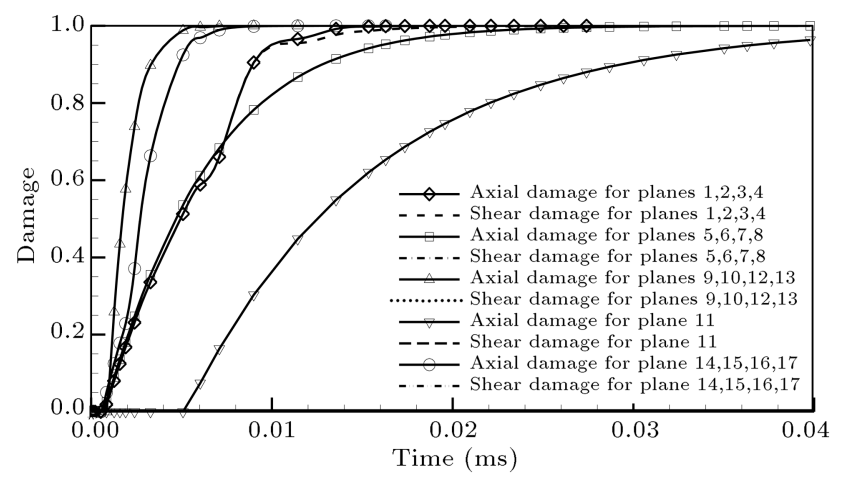

Figure 13. Time domain-damage propagation for both normal and tangential components in the dynamic compression test at a strain rate of $15001 / \mathrm{s}$.

at various strain rates. The response strongly depends on the strain rate. It should also be added that, since the experimental results were not available, the results of this model were verified based on the results of the model by Ragueneau et al. [64].

Figure 13 presents the variation of damage-time for both normal and tangential components in the dynamic compression test at a strain rate of $\dot{\varepsilon}=$ $15001 / s$, to show better trust on the capability of this model for identifying the type and geometry of damages.

Figure 14 is indicative of different equivalent strain rates for each sampling plane with their orientations to the assumption of a constant strain rate of 1500 in the direction of the $x$-axis during the test. As it is obvious in this figure, the equivalent strain rates in various orientations are significantly different from each other and this reveals the necessity to use the multi-plane theory to clarify the dynamic behavior of concrete.

Three major sources of plasticity, cracking, and time-dependent effects such as creep, shrinkage, temperature, and load history cause the nonlinear behavior

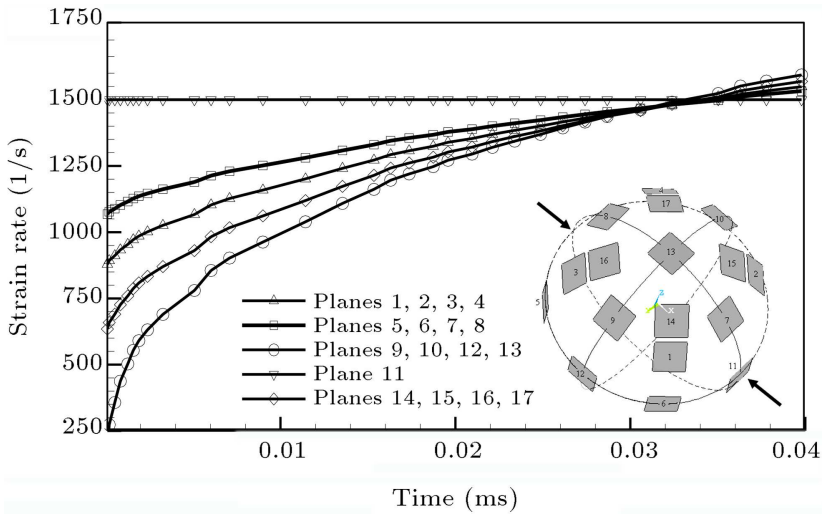

Figure 14. Time domain-equivalent strain rates for each sampling plane in the dynamic compression test at a strain rate of $15001 / \mathrm{s}$.

of concrete [65]. As observed above, this nonlinear behavior has been well simulated by the proposed model.

\section{Conclusions}

In order to have realistic structural analysis results, under low or high velocity loading, the effects of the orientation dependency and loading rate on concrete behavior are essential parameters, which should be taken into account. The loading rate may have significant effects on the behavior of concrete structures, e.g., increased dynamic load bearing capacity, damage retardation, and the change of crack pattern in comparison with the quasi-static case. In view of the dynamic character of the test, the effects of inherent material heterogeneity, tri-axial boundary effects, stress and strain, and strainrate distributions throughout the members are not uniform during dynamic loading clearly. Furthermore, many inelastic physical phenomena such as slip, friction, and tensile cracking are related to surfaces. All these sources of non-uniformity of the response and the resulting progressive damage, which are linked to the orientation, are well captured by the numerical mesoscale simulations. Consequently, a constitutive multi-laminate rate-dependent damage model for the mechanical behavior of quasi-brittle material specimens under different compressive and tensile loading rates was developed using the composition of a modified theoretical multi-laminate framework and damage approach, which can be regarded as a semi-multiscale and semi-empirical modeling approach. The proposed model is double-constraint multi-plane, which satisfies both equilibrium and compatibility conditions, simultaneously.

In the proposed multi-laminate rate-dependent damage model, two new damage functions, namely axial damage and shear damage, which are well consistent with the Mohr-Coulomb failure criterion, are 
introduced for each sampling plane, in which both damage functions are functions of strain components. For simulation of nonlinear aspects such as hardening and softening behavior, in any time step of numerical calculation for each sampling plane, on account of allocation of three strain components to it, one normal and two others tangent to the plane, there are two specific damage function values, which can occur on each sampling plane. Consequently, the stiffness degradation is evaluated with a discrete set of predefined directions for any physical point of the material to consider damage state data all around it. Also, with the aim of strain rate effects modeling, the threshold strain and the elastic modulus increase once the strain rate increases. In this model, there are totally three free parameters, in which two parameters ' $a_{a x}$ ' and ' $a_{a x}$ ' are always activated and parameter ' $b$ ' is activated only under dynamic loading. Because of this, the proposed model is able to predict the concrete behavior under any arbitrary strain/stress path or change of 6 strain/stress components of cubic element with different loading rates by some model parameter requirements.

The suggested model in this research enjoys several salient features such as pre-failure configuration of the inner material, final failure mechanism, the ability to see induced/inherent anisotropy, strain rate sensitivity, and any fabric effects on material behavior. However, the basis of this proposed model is logical and can be easily perceived.

\section{Acknowledgment}

The authors would like to thank anonymous reviewers for their comments, which helped to improve the manuscript.

\section{References}

1. Luding, S. "Introduction to discrete element methods: basic of contact force models and how to perform the micro-macro transition to continuum theory", European Journal of Environmental and Civil Engineering, 12(7-8), pp. 785-826 (2008).

2. Cusatis, G., Pelessone, D., and Mencarelli, A. "Lattice discrete particle model (LDPM) for failure behavior of concrete", Cement and Concrete Composites, 33, pp. 881-890 (2011).

3. Bousikhane, F., Rezakhani, R., Smith J., and Cusatis, G. "Calibration and validation of concrete model for the simulation of the quasi-static and dynamic response of concrete structures", 9th International Conference on Fracture Mechanics of Concrete and Concrete Structures (FraMCoS-9), Brekeley, USA (2016).

4. Rezakhani, R. and Cusatis, G. "Asymptotic expansion homogenization of discrete fine-scale models with rotational degrees of freedom for the simulation of quasi-brittle materials", Journal of the Mechanics and Physics of Solids, 88, pp. 320-345 (2016).

5. Rezakhani, R., Zhou, X., and Cusatis, G. "Adaptive multiscale homogenization of the lattice discrete particle model for the analysis of damage and fracture in concrete", Available on: http://arxiv.org/abs/1702.00695.

6. Shahbazi, S. and Rasoolan, I. "Meso-scale finite element modeling of non-homogeneous three-phase concrete", Case Studies in Construction Materials, 6, pp. 29-42 (2017).

7. Le Nard, H. and Bailly, P. "Dynamic behavior of concrete: the structural effects on compressive strength increase", Mechanics of Cohesive-Frictional Materials, 5(6), pp. 491-510 (2000).

8. Tu, Z. and Lu, Y. "Modifications of RHT material model for improved numerical simulation of dynamic response of concrete", International Journal of Impact Engineering, 37(10), pp. 1072-1082 (2010).

9. Abrams, D.A. "Effect of rate of application of load on the compressive strength of concrete-Part 2", ASTM Journal, 17, pp. 364-377 (1917).

10. Reinhardt, H.W. and Weerheijm, J. "Tensile fracture of concrete at high loading rates taking account of inertia and crack velocity effects", International Journal of Fracture, 51(1), pp. 31-42 (1991).

11. Mechteherine, V., Millon, O., Butler, M., and Thoma, K. "Mechanical behavior of strain hardening cementbased composite under impact loading", Cement and Concrete Composites, 33(1), pp. 1-11 (2011).

12. Chen, X., Bu, J., and $\mathrm{Xu}, \mathrm{L}$. "Effect of strain rate on post-peak cyclic behavior of concrete in direct tension", Construction and Building Materials, 124(16), pp. 746-754 (2016).

13. Chen, X., Huang, Y., Chen, C., Xu, L., and Fan, $\mathrm{X}$. "Experimental study and analytical modeling on hysteresis behavior of plain concrete in uniaxial cyclic tension", International Journal of Fatigue, 96, pp. 261269 (2017).

14. Freund, L.B. "Crack propagation in an elastic solid subjected to general loading-I. Constant rate of extension", Journal of the Mechanics and Physics of Solids, 20(3), pp. 129-140 (1972a).

15. Freund, L.B. "Crack propagation in an elastic solid subjected to general loading-II. Non-uniform rate of extension", Journal of the Mechanics and Physics of Solids, 20(3), pp. 141-152 (1972b).

16. Ozbolt, J., Rah, K.K., and Mestrovic, D. "Influence of loading rate on concrete cone failure", International Journal of Fracture, 139(2), pp. 239-52 (2006).

17. Ozbolt, J., Sharma, A., and Reinhardt, H.W. "Dynamic fracture of concrete-compact tension specimen", International Journal of Fracture, 48(10), pp. 15341543 (2011). 
18. Xiao, J., Li, Z., Xie, Q., and Shen, L. "Effect of strain rate on compressive behaviour of high-strength concrete after exposure to elevated temperatures", Fire Safety Journal, 83, pp. 25-37 (2016).

19. Yu, X., Chen, L., Fang, Q., Ruan, Z., Hong, J., and Xiang, J. "A concrete constitutive model considering coupled effects of high temperature and high strain rate", International Journal of Impact Engineering, 101, pp. 66-77 (2017).

20. CEB (Comite Euro-International du Beton), CEB-FIP Model Code 1990-Design Code, 6th edition, Thomas Telford, Lausanne, Switzerland (1993).

21. Hao, Y., and Hao, H. "Influence of the concrete DIF model on the numerical predictions of $\mathrm{RC}$ wall responses to blast loadings", Engineering Structures, 73, pp. 24-38 (2014).

22. Huang, L.C., Li, J., Tue, N.V., Nemecek, J., and Puschel, T. "Numerical aspects of micro-plane constitutive models for concrete", Applied Mathematical Modeling, 41, pp. 530-548 (2017).

23. Sanchez, F., Prat, P.C., Galavi, V., and Schweiger, H.F. "Multilaminate and Microplane Models: Same Principles and Different Solutions for Constitutive Behaviour of Geomaterials", 12th International Conference on International Association for Computer Methods and Advances in Geomechanics (IACMAG), Goa, India (2008).

24. Labibzadeh, M. and Sadrnejad, S.A. "Mesoscopic damage based model for plane concrete under static and dynamic loadings", American Journal of Applied Sciences, 3(9), pp. 2011-2019 (2006).

25. Bazant, Z.P. and Oh, B.H. "Microplane model for fracture analysis of concrete structures", Report No. ADP001715, Technological Institute, Northwestern University, Evanston. pp. 49-55 (1983).

26. Pande, G.N. and Sharma, K.G. "Multilaminate model of clays - a numerical evaluation of the influence of rotation of principal stress axes", International Journal of Numerical and Analytical Methods in Geomechanics, 7(4), pp. 397-418 (1983).

27. Cusatis, G. and Zhou, X. "High-order microplane theory for quasi-brittle materials with multiple characteristic lengths", Journal of Engineering Mechanics, 140(7), pp. 1-10 (2013).

28. Bazant, Z.P., Adley, M., Carol, I., Jirasek, M., Akers, S., Rohani, B., Cargile, J. and Caner, F. "Largestrain generalization of microplane model for concrete and application", Journal of Engineering Mechanics, 126(9), pp. 971-980 (2000a).

29. Brocca, M. and Bazant, Z.P. "Microplane constitutive model and metal plasticity", Applied Mechanics Reviews, 53(10), pp. 265-281 (2000).

30. Caner, F.C. and Bazant, Z.P. "Microplane model M7 for plain concrete. I: Formulation", Journal of Engineering Mechanics, 139(12), pp. 1714-1723 (2013a).
31. Sadrnejad, S.A. "A general multi-plane model for postliquefaction of sand", Iranian Journal of Science and Technology, Transaction B, Engineering, 31(2), pp. 123-141 (2007).

32. Caner, F.C., Bazant, Z.P., and Cervenka, J. "Vertex effect in strain-softening concrete at rotating principal axes", Journal of Engineering Mechanics, 128(1), pp. 24-33 (2002).

33. Galavi, V., and Schweiger, H.F. "Nonlocal multilaminate model for strain softening analysis", International Journal of Geomechanics, 10(1), pp. 30-44 (2010).

34. Bazant, Z.P. and Oh, B.H. "Microplane model for progressive fracture of concrete and rock", Journal of Engineering Mechanics, 111(4), pp. 559-582 (1985).

35. Sadrnejad, S.A. and Hoseinzadeh, M.R. "An anisotropic multi-plane elastic-damage model with axial and shear damage and its application to concrete behavior", Scientia Iranica, 24(5), pp. 2202-2212 (2017).

36. Bazant, Z.P. and Prat, P.C. "Microplane model for brittle plastic material: I. Theory", Journal of Engineering Mechanics, 114(10), pp. 1672-1688 (1988a).

37. Kazemi, M.T. and Vossough Shahvari, F. "Mixed mode fracture of concrete: An experimental investigation", Scientia Iranica, 11(4), pp. 378-385 (2004).

38. Ozbolt, J., Sharma, A., Irhan, B., and Sola, E. "Tensile behavior of concrete under high loading rates", International Journal of Impact Engineering, 69, pp. 55-68 (2014).

39. Zheng, D. and Li, Q. "An explanation for rate effect of concrete strength based on fracture toughness including free water viscosity", Engineering Fracture Mechanics, 71(16-17), pp. 2319-2327 (2004).

40. Zhang, XX., Ruiz, G., Yu, R.C. and Tarifa, M. "Fracture behavior of high-strength concrete at a wide range of loading rates", International Journal of Impact Engineering, 36(10-11), pp. 1204-1209 (2009).

41. Marzec, I. and Tejchman, J. "Coupled elsto-plastic model with non-local softening enhanced by viscosity to describe dynamic concrete behavior", In Proceeding of the 8th International Conference on Fracture Mechanics of Concrete and Concrete Structures, Barcelona (2013).

42. Kwak, H.G. and Gang, H. "An improved criterion to minimize FE mesh-dependency in concrete structures under high strain rate conditions", International Journal of Impact Engineering, 86, pp. 84-95 (2015).

43. Eibl, J. and Schmidt-Hurtienne, B. "Strain ratesensitive constitutive law for concrete", Journal of Engineering Mechanics, 125(12), pp. 1411-1420 (1999). 
44. Haussler-Combe, U. and Kitzig, M. "Modeling of concrete behavior under high strain rates with inertially retarded damage", International Journal of Impact Engineering, 36(9), pp. 1106-1115 (2009).

45. Malvar, L.J. and Ross, C.A. "Review of strain rate effects for concrete in tension", American Concrete Institute Materials Journal, 95(6), pp. 735-739 (1998).

46. Haussler-Combe, U. and Kuhn, T. "Modeling of strain rate effects for concrete with viscoelasticity and retarded damage", International Journal of Impact Engineering, 50, pp. 17-28 (2012).

47. Bischoff, P.H. and Perry, S.H. "Compressive behavior of concrete at high strain rates", Materials and Structures, 24(6), pp. 425-450 (1991).

48. CEB (Comite Euro-International du Beton), CEB-FIP Model Code 2010 - Design Code, 1st draft, Thomas Telford, Lausanne, Switzerland (2010).

49. Gernay, T., Millard, A., and Franssen, J. "A multiaxial constitutive model for concrete in the fire situation: Theoretical formulation", International Journal of Solids and Structures, 50(22-23), pp. 3659-3673 (2013).

50. Grassl, P., Xenos, D., Nystrom, U., Rempling, R., and Gylltoft, K. "CDPM2: A damage-plasticity approach to modelling the failure of concrete", International Journal of Solids and Structures, 50(24), pp. 38053816 (2013).

51. Soltanzadeh, F., Edalat-Behbahani, A., Barros, J.A.O., and Mazaheripour, H. "Effect of fiber dosage and prestress level on shear behavior of hybrid GFRPsteel reinforced concrete I-shape beams without stirrups", Composites, Part B: Engineering, 102, pp. 5777 (2016).

52. Edalat-Behbahani, A., Barros, J.A.O., and VenturaGouveia, A. "Three dimensional plastic-damage multidirectional fixed smeared crack approach for modelling concrete structures", International Journal of Solids and Structures, 115(116), pp. 104-125, (2017).

53. Grassl, P. and Jirasek, M. "Damage-plastic model for concrete failure", International Journal of Solids and Structures, 43, pp. 7166-7196 (2006).

54. Carrazedo, R., Mirmiran, A., and Hanai, J.B. "Plasticity based stress-strain model for concrete confinement", Engineering Structures, 48, pp. 645-657 (2013).

55. Edalat-Behbahani, A., Barros, J.A.O., and VenturaGouveia, A. "Application of plastic-damage multidirectional fixed smeared crack model in analysis of RC structures", Engineering Structures, 125, pp. 374-391 (2016).

56. Edalat Behbahani, A., Barros, J.A.O., and VenturaGouveia, A. "Plastic-damage smeared crack model to simulate the behavior of structures made by cement based materials", International Journal of Solids and Structures, 73(74), pp. 20-40 (2015).

57. Van Mier, J.G.M. "Multi-axial strain-softening of concrete", Materials and Structures, 19(3), pp. 179-200 (1986).
58. Karsan, I.D. and Jirsa, J.O. "Behavior of concrete under compressive loading", Journal of Structural Division, ASCE, 95(12), pp. 2535-2563 (1969).

59. Van Mier, J.G.M. "Strain-softening of concrete under multi-axial loading conditions", Ph.D. Thesis, Die Technische Hogeschool Eindhoven, Eindhoven, Netherlands (1984).

60. TH Tan, Andrew "Effects of tri-axial stress on concrete", 30th Conference on Our World in Concrete \& Structures, pp. 23-24, August, Singapore (2005).

61. Petersson, P.E. "Crack growth and development of fracture zones in plain concrete and similar materials", Report Number TVBM 1006, Lund Institute of Technology, Lund, Sweden (1981).

62. Grote, D.L., Park, S.W., and Zhou, M. "Dynamic behavior of concrete at high strain rates and pressures: I. Experimental characterization", International Journal of Impact Engineering, 25(9), pp. 869-886 (2001).

63. Song, Z., and Lu, Y. "Mesoscopic analysis of concrete under excessively high strain rate compression and implications on interpretation of test data", International Journal of Impact Engineering, 46, pp. 41-55 (2012).

64. Ragueneau, F., Gatuingt, F., and Bailly, P. "Inelastic behavior modelling of concrete in low and high strain rate dynamics", Computers and Structures, 81(12), pp. 1287-1299 (2003).

65. Omidi, O. and Lotfi, V. "Numerical analysis of cyclically loaded concrete under large tensile strains by the plastic-damage model", Scientia Iranica, 17(3), pp. 194-208 (2010).

\section{Biographies}

Seyed Amirodin Sadrnejad who passed away in 2018, was a Professor in the Department of Civil Engineering at K.N. Toosi University of Technology, Tehran, Iran. The deceased had more than three decades of professional experience in civil and structural engineering and published numerous papers in international and refereed journals and conferences in his specialized field contained numerical methods, material modeling, structural mechanics, and nonlinear analysis of structures.

Mohamad Reza Hoseinzadeh was born in 1986 and received his BSc degree in 2008 from Shahid Rajaee University, Tehran, Iran, and MSc degree in 2010 from Shahid Chamran University, Ahvaz, Iran, with a GPA of 18.55 out of 20 . He was the first-rank student in both BSc and MSc programs. He obtained his $\mathrm{PhD}$ degree from K.N. Toosi University of Technology of Tehran in 2018. His research interests lie in the scopes of material modeling, fracture mechanics, numerical method, nonlinear analysis of structures, and design of seismic and blast resistant structures. 